\title{
Dance as activism: The power to envision, move and
}

\author{
change
}

\author{
Sherry Badger Shapiro \\ Meredith College \\ USA
}

Abstract

\begin{abstract}
This article contains discussion of two main themes relating to the role of dance as activism and the power of dance to envision, move and create change. The first theme concerns practices of doing feminist pedagogy in relation to art, the body and social change. The second theme explores ways in which dance as aesthetic activism is 'haunted by meaning'. These themes intersect through a focus on dance and social justice, and community engagement and this article draws on keynote presentations given to different dance events while I travelled within Aotearoa, New Zealand as Fulbright Specialist in dance in 2015.
\end{abstract}

\section{Introduction}

In the following article, I bring together themes shared within during two different, but connected conferences, as part of my Fulbright work in Aotearoa, New Zealand with The University of Auckland and the University of Waikato Dance programmes in the spring of 2015. While in New Zealand, I gave a third talk at The University of Otago during the conference Moving Communities. All three events had as their major focus dance and social justice, and community engagement. In the following article I have brought together two of the presented talks, adapting the informal style somewhat in writing for this publication. The third talk is available at my website: http://www.sherryshapirodanceeducation.info/.

To introduce this article, I must begin by acknowledging the moments I shared with people I have had the good fortune to meet and dialogue with, observe, listen to and create with. All these people remain with me in my continued thinking and doing in the field of dance theory and pedagogy, directed toward ideas of justice, compassion and community engagement.

Throughout this article, I integrate different forms of personal experiences, academic writing and 'body exercises' as I did in the presentations. I discuss my 
work, both theoretically and practically, what I am interested in, why, and how that came to be. For those readers who are dancers, you will read how my dance experiences gave me insight into a pedagogy that draws upon body knowledge and feminist pedagogy. For those readers interested in the broader issue of aesthetics, I discuss a notion of a radical aesthetics that is about human freedom and selfdetermination connected to radical transformation. In the second part of this article, I discuss the possibilities of art and address dance as aesthetic activism.

Throughout this article, I use the terminology of dance education. By dance education, I mean any form of work through dance where one is working with another in a role as a teacher, choreographer or artist, as we are all involved in educating in some form. I also discuss public education. I understand that in New Zealand the terms 'state schools' and 'state-integrated schools' may be more familiar than how I might use the terms 'public', 'charter' or 'magnet' schools in the context of the United States of America.

\section{Doing feminist pedagogy; art, the body and social change}

The body knows and re-members even in the silences of our lives. In dance the familiar can become strange ... more than movement it is the act of transformational possibility (Shapiro, 2015, p. 67).

\section{Beyond dancing ... that mode of being called teaching}

As Twyla Tharp said, modern dance is more not less (2013). I would also comment that 'teaching dance is more not less'. Only those who have not been teachers hold to the old adage, 'those who can't dance teach'. What we as educators have come to know is that teaching demands us to know something about 'what is' and 'what is possible' of our students and of our discipline. Some important questions that confront us as dance educators are: 'What should we teach?', 'How should we teach?', 'Who should we teach?', 'What is the role of the teacher?', and most importantly, 'For what are we teaching?'

Asking the question 'what is' brings us to question dance. Is it a discipline? Is it an art form? Is it a way of learning about other disciplines? Is it something to learn in itself? Can it tell us something about our cultures and ourselves? Is it a way of knowing the world, or something to know? Can it tell us about the human condition? These are visionary questions that demand us to examine dance in the broader context of education. They asked of us to name what it is we care about, what concerns us, and further, what our vision for humanity is and how education 
gives shape to the articulated vision. I am reminded of the time I interviewed with one of the faculty from my doctoral program. He asked me; 'What would your world be like if there was no such thing as dance?' His question brought me to seriously reflect upon the significance of dance in my life. Since that day, I have found many answers to that question, but it is the question that remains as part of my thinking about dance and about dance education.

James MacDonald, scholar and educator, asked two specific and related questions in his classes that followed in my studies; What does it mean to be human? and How shall we live together in the world? (MacDonald, 1965). These questions take us beyond dance recognising the moral and political connections that accompany any act of education. It is an act of transcendence reminding us that education, any education, must engage the life-world of our students in all of their different narratives that are shaped by ethnicity, harnessed by social class and textured by culture. Which brings me to the question that I wish to address; 'what is the purpose of education?'

In the United States of America, educators are compelled to concern themselves with a technical discourse, discussing little about the moral, spiritual and social values that are the deep purpose of education so that young people are empowered to participate in Tikkun Olam (in Hebrew this means to heal, transform and repair the world). That is to say, we focus on the 'how' rather than the 'why' of education. We discuss test scores not social responsibility, we test facts not compassionate acts, we discuss composition and not purpose, and we examine extensions and not intentions. These are some of the concerns I am raising as I want to consider dance in terms of a moral educational discourse; to examine how embodied knowing can provide a rich and powerful source for self and social transformation; to introduce a critical pedagogy of dance that challenges the boundaries and traditions of dance education; and finally, to give voice to a vision for dance that might contribute to a broader educational purpose of Tikkun Olam. I must say I have come to feel, like bell hooks (2000), that any education worth its name must elicit the passion, the intellectual curiosity, the moral conviction and the spiritual sensitivity of students.

\section{My own educational narrative}

I grew up in the Blue Ridge Mountains of North Carolina in the United States of America. As a child dancer, as a female dealing with the kinds of concerns that are typical of growing up as a girl, and someone who has struggled to find meaning in 
my professional and personal life, I came to my doctoral program. It was in this program that I was encouraged for the first time to see education as a vehicle for understanding and naming my life concerns, to construct a meaningful framework for my professional work, and to think about how I might connect this work to democratic issues of dignity, equality, social justice and freedom. During this period, I began to pull together the intellectual strands and personal questions that have set the direction of my work for the past twenty-five years. As an educator and dancer, I began to seriously rethink about how, in the Western philosophical tradition, sensual knowledge was abstracted from what is called 'thinking'. As a woman and dancer, my only recourse was to reclaim that which had been taken away. No longer would I be left out of the epistemological conversation. I was determined to reclaim thinking in terms that would acknowledge and affirm what I understood so powerfully: body knowledge. As I gained insight into my own ignorance of, and compliance with, the oppressing structure that excluded what my body 'knew,' I began to search for another story. I was not seeking a 'bornagain experience'. What I needed was the ability to make choices that were liberatory and consistent with my strong sensibilities. It was in critical theory that I was able to ground my philosophy, engage with the ideals of radical democracy, and begin to understand the dynamics of human oppression and alienation in ways more grounded than I had previously understood (Kanpol \& McLaren, 1995). The direction of my existential concerns and pedagogic concerns converged. In encountering other critical educators, I discovered the possibility of integrating my concerns about human existence with questions of pedagogy. It was a sort of moral cementing of thinking and being that helped me in challenging traditional approaches to the teaching/learning experience.

\section{Challenging the taken-for granted}

I was not alone in challenging traditional approaches to the teaching/learning experience. Recent feminist and postmodern scholarship (Seyla Benhabib, Judith Butler, Linda Nicolson, \& Patricia Hill Collins) posed a sharp challenge to our traditional approaches to learning and knowing. In particular, such scholarship has brought to the fore the way that emotions and feelings have been excised from critical rationality. Of course, the body, or embodied knowing, represents an entirely antithetical language to the dominant one found in our schools of education today. We often follow the scientific tradition that seeks objective knowledge in an attempt to understand and represent our world. But the body 
offers different ways of knowing that speak to all that is most gut-wrenching and visceral in our existence (Shapiro, 1999). Indeed, the feeling body, far from being an obstacle to worthwhile or accurate knowing may be the primary vehicle for the "human making and remaking of the world" (Bordo, 1993, p. 227). Coming to know through our bodies means to understand how our desires, beliefs, values, and attitudes have been shaped and instilled in us. To know through our bodies means to recognise how our deepest loves and hates, loyalties and prejudices, become part of us. Knowing through our bodies means too, understanding critically the way our deepest feelings and passions have been structured by the culture in which we live. No education aimed at human transformation of our beliefs and attitudes can ignore this deep substratum of embodied knowledge as it is this kind of knowing that can reveal to us the knowledge of life as "the out-pressing of what we have taken in and contained" (Keleman, 1981, p. 130). What the body 'takes in' and 'contains' is knowledge of our oppression and pain, as well as the way we resist and struggle against suffering. Peter McLaren (1988, p. 190) uses the pedagogical term of "cultural tattooing" as he describes this process where the elements of the dominant ideology are "pressed" into the flesh.

I would like to make this point clearer through a body memory exercise. Drawing on body memories was something that I developed while writing my doctoral dissertation as I tried to find ways to flesh out how we embody cultural values. Recalling body memories was not an easy process. I found the memories at times to be painful as I recalled death; to be humiliating as I confessed my prejudices about my visceral feelings towards those who are obese; and to be liberated recalling times I felt the power of my body (Try this for yourself now).

- Body memory exercise: Try to think about a time that you were silenced; that is a time when you were not allowed to speak, express your opinion, respond, or argue. It may have been yesterday or years ago as a child. There may be many memories but let the one that comes to mind be one that you focus on. It may have been in school, with a friend, a parent, a spouse or partner. It may have been with a person of authority or in a meeting. Whatever your memory is, try to recall where you were, who was there, what were you wearing, what was said or done. Recall the memory. Now recall the feelings that were created from that experience. What did you experience in your body? Recall the memory; see it and feel it. 
- Now please take two or three words or sentences and put those into movement; take a few moments to explore then compose movements to memory.

\section{The dialectical relationship between aesthetics and ethics}

Central to my work has been Terry Eagleton's (1996) assertion that in aesthetics what we are referring to is the sensuous experience of the body. And the most powerful aesthetic experiences are those where we learn to resist those things that constrain or limit our lives. It has been through this denial of the body in education that we have come to believe that reasoning occurs outside the circumstances of our experiences and our life-world. Yet, the opposite is true. Thinking and understanding are inseparable from the language, experience, and culture of historically and socially situated human beings-that is of beings that live their lives as embodied creatures. This insight is surely one of the most significant in recent postmodern and post-positivist scholarship. What human beings come to say or believe about their world is always a situated kind of knowing. It is this body situated and inscribed by culture and history that determines so much about who we are, how others see us, and the sense that we give to our world.

In my own experience growing up during the 1950s and 1960s in the Western Appalachian Mountains, I came to understand my body as something strong, even powerful. The experiences of exploring trails through woods, swinging from grapevines, making houses from fallen leaves, and lying on damp moss, all taught me to understand my world through sensual experience. Coming to know was certainly an embodied experience. Truth, limits, and possibilities were joined and revealed through experience. Freedom was something felt, exhilarating, breathtaking, and powerful. Early in my forming, I learned that freedom came out of decided action and risk taking. I also learned that it felt liberating. I found affirmation in a way of knowing that was not objective or detached, something only outside myself, but something that included me, my own experiences. I learned not only about the woods, trees, and earth; I learned about myself as I felt and engaged these things. My being-in-the-world was meaningful, my presence necessary to bring my world into being. What I mean by this is that my sensual understandings had immense importance in the structuring of my being and just how it is that I related to others and the environment. My body was the mediator of experience, and knowledge was about my subjective interaction with my world. Entering school, I learned that coming to know did not include body knowledge. My 
physical being, which felt pain, joy, tiredness, exasperation, love and energy, possibility and freedom, was to be ignored (when it was not thoroughly controlled). Indeed, I came to understand my body as some 'thing' to be controlled. And sensual knowing was simply excised from the process of learning. Philosophically speaking, my body became it, rather than is; knowledge as objective, rather than subjective.

It is important to reiterate here that most of what is found within dance education in the United States continues to resemble Paulo Freire's (1968) notion of the 'banking concept' of teaching. Students learn to silence their own voices, obey authority without questioning, and follow accepted traditions. We ask students to become 'bodiless beings', or 'nobodies'. We ask them to alienate themselves from their feelings, from their aesthetic or bodily experiences with an emphasis on cerebral knowledge. As Stanley Keleman (1981, p. 124) writes, “It's our emphasis on knowing that enables the brain to feel that it 'has' a body.... Then, rather than being somebody, we have a body." To begin to include an embodied language in dance education would mean more than students sitting at desk learning historical facts taught from one perspective, or memorising poems. It would be a pedagogy that involves the student in critical reflection of their world in terms of issues of power, control, and moral or ethical sensitivity, much of these understood as mediated through the somatic lives of individuals. It calls for a critical pedagogy of the body.

Firstly, I offer a definition to critical pedagogy and then consider its limitations. Critical pedagogy takes to heart the possibility of education engaging in a process of where people's pain, suffering, humiliations and injustices are accounted for and where our energies are used in reshaping and remaking our human situations into ones which are more caring, loving, just and compassionate. It speaks with a vision and commitment to education where moral and social good is the central purpose. Peter McLaren (1989, p. 160) gives words to the foundational principles: 'Critical pedagogy,' he states, “resonates with the sensibility of the Hebrew symbol of Tikkun Olam," as discussed earlier, which means 'to heal, repair, and transform the world.' It provides historical, cultural, political, and ethical direction for those in education who still dare to hope. What McLaren is raising is a vision of education that goes beyond the language of jobs, beyond test scores, beyond a system that seeks to track students into particular social roles. Giroux and Simon (1988) summarise the concerns of education that is organised around critical pedagogy. 
This means that teaching and learning must be linked to the goals of educating students: to understand why things are the way they are and how they got to be that way; to make the familiar strange and the strange familiar; to take risks and struggle with ongoing relations of power from within a life-affirming moral culture; and to envisage a world which is "not yet" in order to enhance the conditions for improving the grounds upon which life is lived. (Giroux \& Simon, 1988, p. 13)

Such pedagogy engaged in ideological critique inevitably raises moral concerns. It exposes questions of social injustice, inequality, asymmetrical power, and the lack of human rights or dignity. This educational discourse is meant to provide a theory and a process for critiquing all that privileges some rather than all separating us into categories of those who deserve to live well and those who do not. Critical inquiry here means to learn to question what we take for granted about who we are and how the world functions. Essential to critical pedagogy is a kind of understanding where students come to 'make sense' of their lives as they come to an awareness of the dialectical relationship between their subjectivity and the dominant values that shape their lives. These values may be ones fixed locally though now days they are more likely to be part of a global ideology that is centred on ever increasing consumption of the earth's resources and intensifying competition between workers. The validation of personal experience is central to the kind of knowing that enables students to 'find their voices.'

I return now to a body memory exercise, as I want to continue to bring theory back to personal experience as a process that connects embodied knowing to understanding something about the social context within which it is created. (Try this now).

- Body Memory Exercise: Remember a time you were silenced, but this time it is an experience where you spoke but no one listened or heard what you said. For example at a convention or meeting you offered your thoughts and the conversation continues as if you did not speak; or what you say is incorrect until you say what is wanted to be heard like in a classroom where the teacher is looking for the correct answer, or when you give the wrong interpretation to a poem. Recall the experience as it returns to your consciousness. Recall the details. Now recall how your body felt. What did you feel in this situation? 
- Again, take two or three words or sentences and create a movement phrase. Now add that phrase to your first phrase.

My memories, your memories, are constructed out of the discourses and the culture in which we have lived. In my own work, I have been interested in a critical pedagogy that is concerned with our embodied lives and that gives attention to the ways we perceive, live in, live with, and through our bodies. An example of this is in my choreographic work, created at Meredith College (a private college for women). In a choreographic work, I asked students to engage in a process where they use their own body knowledge to critically reflect upon their own lives, but particularly in relationship to the social and cultural values and situations that shape them. The cultivation of critical understanding through this process is to serve both the dancer and the dance. It is an aesthetic education that is about learning to see our lives in new ways with new possibilities. It is this form of dance and aesthetic education that I especially want to draw attention to. It is concerned with the body lived, the body/subject, and takes seriously the body as that which mediates between self and society, material and the transcendent; between perception of appearances and hermeneutical understanding; between body emptied of meaning and the body full of memories. As Andrea Dworkin (1987, p. 25) reminds us "the skin marks the space between inner and outer worlds, it presents race and moulds to gender, and it mediates both gentle caresses and harsh abuses." Perhaps, then it is the body, more than anything in our diverse and complex world that unites us in recognition of our shared fragility and our common human condition? This is one more reason to value the work we do as educators of the body. Who more than we appreciate the potential beauty, the extraordinary capabilities, as well as the delicate vulnerabilities, of that which all of us share?

\section{A pedagogy of possibility}

Taking care not to diminish the importance of difference, as there is much left to be done in the way of adequately recognising and valuing all of our diverse experiences, cultures and traditions, I nonetheless want to draw attention to how we might organise through our commonalities. Perhaps it is seeing the fear, suspicion and hate that is so rampant in the world today that makes me want to search for and affirm our common human attributes. It is the commonalities of our bodies that offer ways of valuing those shared biological, emotional and expressive human characteristics necessary for a more humane world. To address the importance of a common humanity is to understand that the struggle for human 
rights and human liberation are indispensable in a globalised world. The body, our bodies, is what grounds our commonalities. For those of us who teach, it can be the starting point for developing children who are more sensitive, caring, connected and tolerant of others. It calls for a pedagogy of possibility, and it is in pedagogy where I seek what is possible. In other words, the real purpose of dance education is in that search for meaning. Human beings need more to satisfy us than material things. We need to see purpose and significance in our lives. None of us, especially the teacher, can or should be separated from the experiences, traditions and relationships that make our lives full and rich. Teaching is a mode of being in the world that requires of us to think about what it is that gives our students or us a sense of significance in our lives. So often teaching is treated as if it were a scientific experiment concerned with exact and standardised results that can be uniformly measured for everyone. In doing this we deny the personal, the intentional and situational. More directly, it means denying who we are, why we are here and what is this life all about. Teachers must never lose the connection between work and the spiritual, moral and human dimensions of our students' lives or our own. Schools are not places to process inert matter but opportunities for young lives to realise their possibilities. Please participate in the last body memory exercise to complete the process.

- Body Memory: Recall a time that you chose not to speak; where silence became your power or form of resistance.

- Explore and create from your memory. Then connect it to your other two movement studies as best you can recall.

It is significant to understand that we create dance, but dance also creates us. Dance always mediates or expresses who we are and how we live within time and culture. In this sense, dance is nothing more than a text written by the body signifying how we experience and give meaning to our world. And it is here, through this text written by the human body, that we can begin to engage in the process of recognising and transcending the limitations and boundaries that up to now have closed off new possibilities. We can discover new ways to live; expand our sense of being; and establish new relationships with those who share our world (Shapiro \& Shapiro, 2002). In other words, pedagogic practices that draw upon the body and aesthetic processes as ways of understanding the world and our selves can be a starting place for dance educators to contribute to a more humane, just and loving global community. 


\section{Art as the impossible}

Like nothing else in the education of our children, art offers ways to transcend a consciousness that fixes our world as if it is something that is unchangeable. It provides an avenue for us to see the 'what is' of our world and to imagine 'what might be.' And, as it nurtures the imagination of children and attends to their perceptions, it helps to develop them so that they are able to re-imagine and reshape their world. Here is where art lays the groundwork for addressing the challenges and possibilities for changing our world. We can begin to understand the critical responsibility of art in a world where children are taught to accept and conform to 'what is' and not to question what they are taught or their own experience. Though art cannot, nor should it, be a direct mirror of life, it should tell us about life in ways that, as Maxine Greene (1988) says, "makes the familiar strange and the strange familiar". In other words, it should help us to see what was obscured or hidden before, and help us to imagine that which was unimaginable. Arts education, then, becomes revolutionary as it shows us reality in ways that heighten our perceptions, and presents images to us of what might be possible or preferable.

As dance educators, we can assist children in learning how to give voice to their life-stories through dance. Not only is moving their own stories pedagogically valuable as a way to deepen our understanding of who we are, but also moving them for others provides a place for students to share their stories. In voicing their stories a dialogue can begin. In learning how to represent the world as they experience it they become better able to see themselves in others, and better able to develop that empathy for the life of another that a true and just community demands. As Bauman suggests, (in Smith, 1999, p. 181), they are able to reach towards a place where they may "grasp hold of the self and awaken it as an active moral agent disposed to care for the 'Other'.

We have the opportunity to work with children and young people in ways that affirm their identities, challenge their taken-for-granted assumptions, and impart a way of being in the world that is compassionate, critical, creative and bound up with a vision for a more just global community. Such a community unlike our present fragmented and competitive world would be a place we can count on, where we understand each other, where we are never an outcast or a stranger, where we trust each other, and where we are safe and our well being assured. While such a community represents the kind of world that is not yet available to us, it is, I believe, this kind of community that is loving and just that our children 
need and deserve. And it is one for which, we as educators, must struggle to make possible.

Let me say in closing that these are perilous times for those of us concerned with arts in education, indeed for any of us who believe in some progressive or humane vision of public education. Schools in my own country, and across the globe are increasingly awash in a spiral of ever increasing standardised testing. It seems to me that there is a great need to continue to assert the crucial importance of the arts in our schools, at least where the arts express a perspective on education which values the importance of our children developing themselves as thoughtful, imaginative, sensitive and socially responsible citisens. Let us speak the pedagogic language of Tikkun Olam and make dance the place where we affirm the dignity, beauty and fullness of life.

\section{Haunted by meaning: Dance as aesthetic activism}

In this section, I explore the concept of aesthetic activism as a means to further social justice and compassionate community. Drawing on critical and feminist pedagogies, I connect a choreographic process that centers on the body as a site for self and social awareness and a critical understanding of the context of women's lives.

The 'aesthetic' here is understood as that domain in which dominant meanings are disclosed and possibilities for social change can be imagined and realised. I describe a community dance project in Cape Town South Africa that makes concrete just how embodied knowledge along with critical understanding can be utilised to create a dance performance. This kind of pedagogy suggests ways in which meaning and purpose within a changing global context can be grounded in an ethics of social justice, human rights and inclusive community.

\section{Finding dissonant realities and challenging fixed meanings}

In the summer of 2011, while riding in a taxi in Tel Aviv, we turned onto Rothschild Boulevard, one of Tel Aviv's oldest leafy and affluent streets, we came upon tents erected in the grassy median. Indeed an unusual site. Above the tents were banners with the phrase 'Aesthetic Activism'. I asked the driver why the tents were there. He mumbled something about people not being happy about the housing situation. With little research, I learned that the tents were a chosen aesthetic act, an act that sought to bring attention to the dissonance between existing 
inequalities around access to affordable housing. This intertwining of the aesthetic and political has become central in struggle from New York to Cairo to Greece and Russia. In places around the world activists have found ways to challenge social and economic injustices through creative forms of expression. In so doing, they have created "communities of solidarity and resistance" (Welch, 1985).

In my work I draw on social theories including Terry Eagleton, Maxine Greene, and Herbert Marcuse as well as contemporary feminist theory as they intersect with activists art making. The central concern of this discussion focuses on how aesthetic processes are joined to feminist and critical pedagogies creating spaces in the classroom, studio, or community as of understanding and conscious engagement with one's life. As Maxine Green (1988, p. 2) refers to the work of Virginia Woolf in her book The Dialectic of Freedom to describe what Woolf called, breaking of the disinterest of twentieth-century artists referring to their absence of care. In contrast Woolf goes on,

... to break with the 'cotton wool' of habit, or mere routine, of automatism, is to seek alternative ways of being, to look for openings. To find such openings is to discover new possibilities-offer new ways of achieving freedom in the world. (Green, 1988, p. 2)

Here we imagine that it is possible to reinterpret lived experience challenging fixed meanings and by so doing, seeing oneself or one's world in a new perspective. This questioning and sense-making helps to shed some light on the common sense world that is always perspectival and therefore incomplete. Part of the work is to transcend our particular viewpoint recognising there are always multiple perspectives and multiple vantage points, and therefore no accounting can ever be complete or finished. As Greene (1998, p. 128) reminds us, "There is always more. There is always possibility. And this is where the space opens for the pursuit of freedom."

I illustrate my understanding of aesthetic activism in dance pedagogy through my recent experience within a community of the Western Cape, in South Africa. Taking the body, and in particular hair as the thematic focus, I describe the way that the "familiar can become strange, and the strange familiar" (Greene, 1988) so that assumptions grounded in our everyday world can become a catalyst for a transformed understanding of identity, race and gender. The boundaries for girls and young women's bodies and the narrow definitions of femininity are the central theme. Laid to bare are the struggles to change the historical normative standards 
for femininity, power and distinctions of identity as a society is shifting its political ideas. In this sense, dance becomes a process of aesthetic activism in which the body provides a concrete history for troubling essentialist assumptions and offering alternative possibilities. My intention is to make clear that aesthetic activism can be a catalyst for creating a more meaningful and empathic community. My concern is to illuminate the meaning and possibilities of aesthetic activism as they further the moral agenda of social justice and human rights.

\section{Grounding aesthetic activism in community}

This attention and orientation to aesthetics and activism are always grounded in community. Community is based upon a concept that we exist not alone in the world, but along side with others. Archbishop Desmond Tutu reminds us that one cannot exist as a human being isolated from others. Tutu's vision makes it clear that the quest for community is inseparable from a deep understanding of human connection. For him this is expressed from the African term Ubuntu (Tutu, 2014).

Ubuntu is a concept that we have in our Bantu languages at home. Ubuntu is the essence of being a person. It means that we are people through other people. We cannot be fully human alone. We are made for interdependence; we are made for family. When you have ubuntu, you embrace others. You are generous, compassionate. If the world had more ubuntu, we would not have war. We would not have this huge gap between the rich and the poor.

As we begin to concern ourselves with negotiating this common terrain called community, there is much to be considered as the web of economic and political forces, as well as beliefs, practices and ideologies can deter the practices of community engagement in an attempt to address issues of (in)equity, (in)justice, and ex/inclusion. An intervention into the structures or agendas requires, those of us who choose to work as activist through community engagement, the ability “... to not only understand a wide array of contextual forces", as noted by Collier (2014, p. 5), but also "to design critical interventions that contest unjust and inequitable ideologies and structures...." Though Collier's discussion is not about aesthetic activism, it is relevant to any discussion that is about working within communities using a critical and interpretive praxis framework. This critical view is essential to recognising the multiplicity of cultural subjectivities held within communities. A critical perspective also assist the artist/researcher/community activist in recognising the dynamics of social intersections in terms of race, class, 
gender, sex, sexuality, ethnicity, religious, tribe, regions, or political affiliationsthe myriad of discourses at play in any one gathering of people. A critical orientation grounds the work while the interpretive is needed to help us understand the narratives, lived-experiences and viewpoints of the community members. This integration of the critical and interpretive, as Collier suggest, inform each other. Why one thinks, feels or acts in particular ways can be examined, deconstructed and challenged. Revealing reified norms, or oppressive socially acceptable habits may also assist in identifying particular barriers to taking relevant action or praxis. As we ponder the dynamic complexities of aesthetic activism through community engagement, it is crucial to attend to the participants, the process and what is produced. As our world continues to expand, we must take notice of our limitations and boundaries, and sense of what is beyond.

\section{Transcending limitations and boundaries}

Today we live in a global society where cultural globalisation, the transnational migration of people, information, and consumer culture is prevalent. The creation of dance in this context is no longer limited by space or time. Our ability to experience a virtual world, even as we physically might stay in one place, has changed our sense of boundaries, our sense of place, even our sense of time. Coming to recognise the imaginary or constructed nature of our boundaries, the narratives of country, race or ethnicity and even gender, has spurred us to deconstruct what was referred to earlier as 'real' or 'traditional.' Dance always mediates or expresses who we are and how we live within time and culture. In this sense dance is a text written by the body signifying how we experience and give meaning to our world. And it is here, through this text written by the human body, that we can begin to engage in the process of recognising and transcending the limitations and boundaries that up to now have closed off new possibilities. We can discover new ways to live; expand our sense of being; and establish new relationships with those who share our world (Shapiro \& Shapiro, 2002). The process calls us towards another kind of aesthetic or meaning-making process.

Meaning-making as an aesthetic act looks toward the rational and the sensual, the mind and the body, the individual and the society, the particular and the shared. Or put more succinctly by Eagleton (1990, p. 16); "The aesthetic, then, is simply the name given to that hybrid form of cognition which can clarify the raw stuff of perception and historical practice, disclosing the inner structure of the 
concrete". A global aesthetics then, moves beyond the individual or the self to connect to the other, recognising the concreteness of an ethical existence in a shared world. A language that emerges from our bodily living speaks to a kind of rationality distinct from one that is only intellectually rooted. It speaks to the specificity of individual experiences, and testifies against any simple abstraction of any category or label. This movement from abstract to concrete has been a strong focus in feminist theory and pedagogy (Weiler, 1988). Studying the past, confronting the present, and envisioning a new future have been central to women's liberation movements across the globe. Weiler (1988, pp. 114-115) defines the space where teachers are engaged in feminist pedagogy:

... They are describing the classroom as a place where consciousness is interrogated, where meanings are questioned, and means of analysis and criticism of the social world as well as of a text or assignment are encouraged. For these teachers, the goal of teaching is grounded in a respect for human value and cultural worlds of their students, and what it encourages is the development of both criticism and self-criticism.... Feminist teachers share a commitment to a more just society for everyone, but they have a particular sense of themselves as women teachers and are conscious of their actions as role models for students.

The emphasis in feminist pedagogy has ensured that the personal or subjective, life-stories, are central in understanding how culture and public policies shape lives. In this, we can view how the social worlds in which we form our identity are visceral, they are in our bones and our musculature. Our views of ourselves, of others, our ethics, values, manners of being and relational understandings are instilled in our bodies, a place in which our thoughts and actions are instantiated. The 'body/subject' is the ultimate destination of cultural forming, both local and global. This point of cultural ingestion is where both projections and formations mingle in creating a double-edged process. The body of the postmodern subject as Terry Eagleton states, “... is integral to its identity" (1996, p. 69). For modernity the body was where there is something to be done, a place for betterment, in postmodernity it becomes a place where somethinggasing, imprinting, and regulating-is done to you. And, for the global body imprinting by the concentrated power of the western media is intensified and a sense of a local self becomes less important. 
Human suffering extends through and beyond the boundaries of nationality, race, ethnicity, gender, and social class, sexual or religious preference, all the ways of marking ourselves off from others. Here, in our shared physical suffering, in the commonality of the body, is a place of deeper and mutual understanding, and thus of transcendent possibility. What is required is an aesthetic process that directs us towards critical understanding, empathy, and imagination. Historically, the arts have always played a critical role is helping to see 'what might be'. Dance, particularly, has provided us with ways of understanding culture, history and human desires seeing both who we are and who we might become. Not withstanding how the arts have played other kinds of roles in our cultures such as a form of entertainment, an avenue for escape, or as a form of exercise, here my focus is on dance as a form of intervention in our social realities, as an action for the purpose of effecting self and social change and promoting social justice. This kind of aesthetic action has been cultivated throughout history in different cultures as an avenue of jolting us out of our everydayness, as a process of opening spaces for us to examine what have been designated as socially acceptable ways of being, as a catalyst for challenging labels and restrictions, and as an experience that sensually educates us to think beyond and imagine what is not yet. It is at times called activist art, offering a counter discourse to the official one.

\section{The discourse of activist art}

Activist art means community or public participation as means of effecting social change and promoting social justice. (Rosenberg, 2009, p. 5)

As we have seen in recent examples with activists movements that have utilised aesthetics as a way of making statements such as the recent events in the United States about police brutality on African Americans in the 'Black Lives Matter Movement'. i 


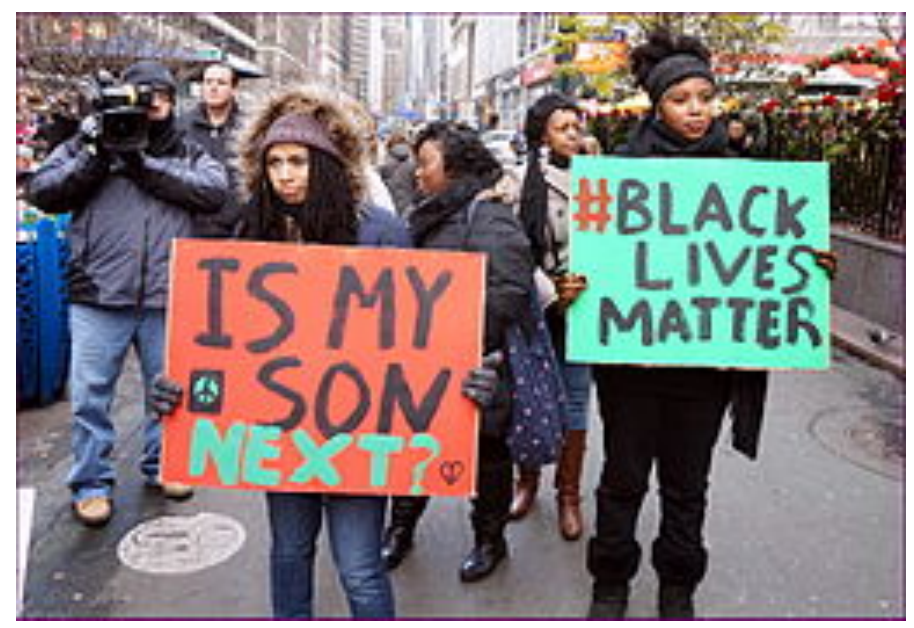

Figure 1: Protestors at a Black Lives Matter demonstration

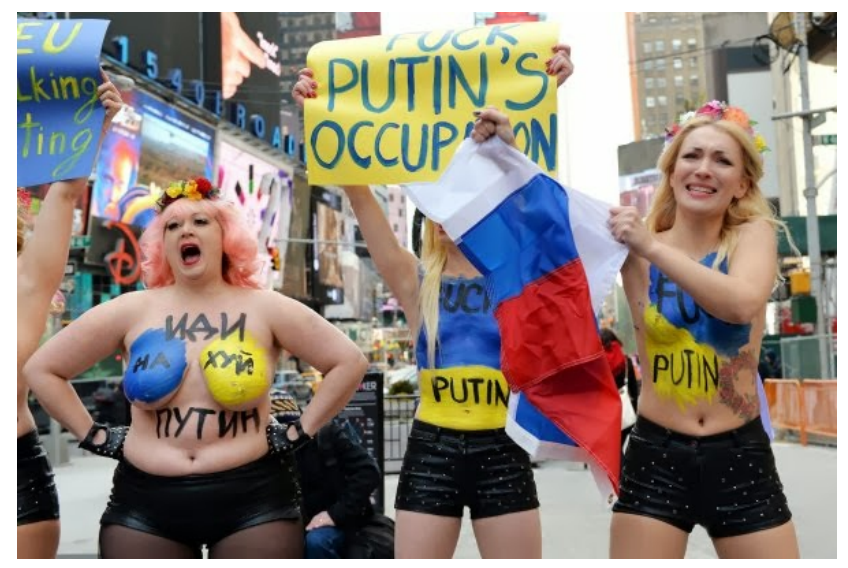

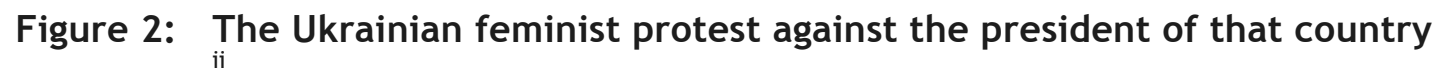

The Arab Spring cyber-protest against corruption and authoritarian governments "iii; the Argentinalan Mothers of the Plaza de Mayo iv; and the "Cloth line Project" to publicise violence against women (to name a few). And protest around Māori rights and claims in your own country over the years ${ }^{v}$. In each of these, we see forms of aesthetic activism. There is for example the emphasis in all of these struggles that the aesthetic is, to quote Picasso, "A deceit that tells the truth." In other words, the aesthetic allows us to exaggerate, condense, highlight social realities in order to focus our attention and mobilise our energies against injustice and other forms of dehumanisation. Rosenberg $(2009$, p. 5$)$ tells us that:

Activist art, in both its forms and methods, is process- rather than object- or product-oriented. Activist art takes place in public sites rather than within the context in art-world venues. As practice it often takes the form of temporal interventions, such as performance or 
performance-based activities, media events, exhibitions, and installations.

Artistic expression becomes inseparable from a politics that seeks to notice what is and, equally important, to imagine what is not yet. In places across the globe, 'flash mobs' refuse the narrowly defined and traditional dance and performance spaces. In fact, it is my contention that wherever there is a politics of resistance to injustice and inequality one will find creative re-imaginings of human possibility. This is true across the performing arts, whether in poetry, theatre, music or dance. Human refusal of the present world is always paralleled by new visions of meaning and discourse expressed well by the Porto Alegre declaration 'another world is possible.' Lucy Lippard (1995), activist, artist and scholar, saw art and politics as linked, for, she believed, they both held "the power to envision, move, and change" (Collins, 1995, p. 10). Of course, it is necessary to add that such aesthetic activism is not restricted to those seeking human progress but is also found in less salutary and reactionary movements. One only has too think about the Nuremberg Nazi rallies as a prime example, or today the 'Tea Party' right wing politics in the United States.

It is worth noting that while the internet and social media have vastly expanded our ability to communicate with others nothing replaces the powerful immediacy of co-present bodies, the shared physical experience, intimacy and warmth that comes from embodied proximity. What gives the aesthetic so much power is that it transforms critical reason into a process that works through emotion, feelings, and the sensibilities of bodies. I heard this action described recently by George Takei (who played Mr. Sulu on Star Trek), as he discussed his new musical about the internment camps for American citizens of Japanese decent, as something that goes straight to the heart and then to the mind. Dance offers an especially rich vehicle for this reverse cognitive process as it can speak directly to the embodied and sensual experience of individual lives. Dance, as a discipline, has also directed itself towards studying the past, as it has also confronted the present. Choreographers have often chosen historical events or life stories to create dance. Gottschild explains (2008, pp. 62-63),

Dance makers have responded to social ills throughout the history of modern dance. Racism captured the imagination of mid-20th-century Americans: Charles Weidman's Lynchtown (1936); Pearl Primus' Strange Fruit and Jim Crow Train (both 1943), and Slave Market (1944); and Katherine Dunham's Southland (1951) all dealt with this issue. In Germany, Kurt Jooss created The Green Table (1932), a 'dance 
of death' about the horrors of war. A new crop of socially engaged works has contemporary artists following in the footsteps of their aesthetic ancestors, particularly since the wake-up call of the 9/11 terrorist attacks. ${ }^{\text {vi }}$ These artists have brought to consciousness, by raising awareness, some of the horrific chapters of human history. Many other examples can be found throughout the dance world. What I want to draw attention to though is not so much the aesthetic product but the aesthetic process.

\section{Tangled theories}

My own struggle to connect dance pedagogy to aesthetic activism has led me through tangled histories from Marx to Imelda Marcos. I have linked the choice of economic systems to the kind of shoes women wear. Subverting the traditional pedagogic formulas for dance, I have been able to re-flesh the dancer to an embodied existence through a choreographic process that makes connections between feminist work and a liberatory pedagogy forming with activist intentions. With my students, we critically examined how we feel about; live in, with and through our own bodies. It is to be noted that, as women, it is in our bodies that we primarily experience who we are, and it is in our bodies that we struggle with issues of self-acceptance, affirmation, social action, and how we relate to other women. Simply stated, we were in a process of re-membering our bodies; "the autobiographical element that adds narrative that is intended to be moving and feel familiar to other in a similar situation" (Rosenberg, 2009, p. 7).

\section{The process}

Pedagogically we begin with the body, the body understood as the concrete material inscribed by cultural values, local and global, and the vehicle for transcending our limited social identities. A pedagogy of the body may direct us towards the recognition of a universal humanity, the still radical idea that all humans share the same inalienable rights. Pedagogic practices that draw upon the body, and aesthetic processes which provide ways of understanding the world and ourselves intellectually, sensually, mentally, and emotionally are all but nonexistent in traditional educational texts, teacher education programs, classroom practices, or dance studios.

I share an example of how one might draw upon embodied knowledge and connect it to social and ethical critique. This act of educating for a kind of activists 
aesthetics cuts across cultures and unites the arts/dance in the struggle for connection, healing (that is overcoming fragmentation and making whole), and compassion. Such a pedagogy engaged in ideological critique inevitably raises moral concerns. It exposes questions of social injustice, inequality, asymmetrical power, and the lack of human rights or dignity. This educational discourse is meant to provide a theory and a process for critiquing all that privileges some rather than all, separating us into categories of those who deserve to live well and those who do not.

In my position as a dance educator/choreographer, I have had the opportunity to evolve in my own thinking about dance education. From the most primitive ways of teaching of having students to reproduce the steps they have been given; progressing on to creative movement, where students learn to create from a movement vocabulary; and finally to a philosophy for education/arts/dance which has as it focus the development of an artistic aesthetic process which takes students through questions of identity and otherness, and, my hopes, towards compassionate and ethically responsible behaviour. I have worked on choreographic projects that examined women's relationship to food, exposing the often-ill results of young girls and women in a dance titled, "Dying to Be Thin". Images of girls and women in the media were a rich ground for exploring ways female identities are being shaped by the media and advertising in the project titled, "Body Parts". The biblical story of Sarah and Hagar's relationship took us through a critical process examining ways in which we choose to include and exclude others, titled “... and, Sarah Laughed”. And there were other themes, all chosen because they offered the students an opportunity to better understand how they thought about, felt and lived out the cultural and historical inscriptions. The process was not simply directed as a project of enlightenment, but rather to deeply question how the culture helps shape that we are and become to be, and what part we ourselves take in this shaping.

\section{The context}

Below I provide a more detailed example of my choreographic work as an example of my pedagogic philosophy. This particular project began with a Fulbright grant in South Africa. Having completed some research concerning how dance education fit into the newly developed post apartheid Democratic Curriculum for the Western Cape I knew this would be fertile ground to research how dance in the schools were helping to meet the curriculum goals directed toward social justice and equality in 
the support of a new democratic state goals. I also had personal contact with the government administrator of the program, as well as a contact in the Dance Program at Cape Town University. Part of my research was structured to gather information about dance programs offered in three different high schools. The other part of my research was structured towards working directly with female dancers from different social/economic and racial backgrounds in a choreographic project. This research project is what became a dance called "hair southAfrica." It was performed for their home communities at the end of the Fulbright Project. I kept in mind what bell hooks (2000, p. 133) taught me, "Talking together is one way to make community."

\section{How do you begin}

The body is the surface of the inscription of events.

$$
\text { (Foucault, 1977, p. 25) }
$$

Working within a community that is twenty years out of an apartheid government and still struggling to make concrete the hopes and dreams they have for a country that is to be grounded in social justice and democratic values, but still too often wears the clothes of the old oppressive regime, I was walking on tender ground. It encouraged explorations of communal identity, as suggested by Collins in her discussions on consciousness-raising (2006, p. 727), of blackness and femaleness, to increase self-awareness accompanied by ideological awakening. These consciousness-raising pedagogies connect the personal and collective stories. And, all stories begin in a context. This is no different. My project began by mapping out a community dance project for young women in South Africa that would engage them in exploring personal experience and collective body memories. The research focused on how dance can contribute to the formation of a national identity oriented towards democratic values. The curriculum was the dancers' own biographies. Through the choreographic process, they were to examine the shaping of their identities and consciousness as young women in the New South Africa. Searching for questions I might ask as an outsider, and one that also could speak to being female and to the society, I chose hair. Hair became the medium for examining questions of race, equality, economic determination and feminism (hair on the head, opposed to other body parts). The process emphasised discussion, dialogue and movement that drew upon readings, written personal reflections on body memories, creating their own movements that reflected their life stories, and utilising a critical dialogical component in order to understand that one is not 
simply 'expressing oneself' but expressing oneself as a member of a culture. Noting here that culture tells you who you are, what you must do, how you can do it, and how you appear.

Throughout the four months of working together a community between diverse groups of young women, some from the townships others from more affluent backgrounds, was created. Creating community dance as defined by Kupper (2006, p. 3) has specific criteria:

- Community dances are communally created; they are not individually authored.

- An artist, who directs and choreographs people towards this goal, if it comes into existence, does not predetermine the end product.

- Community dance's power rests in process rather than product; In the act of working and moving together, allowing different voices, bodies and experiences to emerge.

Kuppers makes clear that the purpose of creating community dance takes seriously the process of creating the dance through the participants. She goes further to clarify how working in community dance is not only an aesthetic process, but can also be a political one.

- Community dance, on the other hand, often aims to enable change both within individuals and within wider social structures.

Here, Kuppers takes the leap into critical pedagogy as she emphasises understanding for empowerment moving beyond individual change, to social change.

After identifying the group, bringing clarity to my own motivations, and coordinating the place and time, I began to further develop methods that I believed could, in a sensitive manner, bring forth a discussion about identity around issues of race, class and gender through body/hair memories. As in any feminist pedagogy, this process valued subjective knowledge, the voice of the knower, and what was known as the 'taken for granted' assumptions. Throughout the process we explored the dynamics between the power of cultural inscriptions and social institutions, and the consciousness of the dancer/participants. 


\section{The choreographer/educator}

I, as the community dance choreography/educator, am not an impartial observer. I come with my own knowledge, experiences and ideologies. I come with a particular ethical view of humanity. Working within this specific situation, clear about my purpose, sensitive to ethical issues, I began this work. My own journey I travelled with them was transformative for me as I was privileged to have heard their stories, to be respected and trusted to lead them through this process of reflection, and to have developed a lasting feeling of creative transformation.

\section{The dancers}

I made it clear to the dancers that this dance would be a story of their own lives developed through this critical/choreographic process where their body memories would provide the impetus for creating movement. Each movement came from their stories, their lives. They ranged from ages 14-22, though most were between 16-20. One group of dancers came from a community based dance project established in 2002 in the Western Cape called The Jikeleza Dance Project (In Xhosa language Jikeleza means turn around). They define their mission as:

To add value and uplift the areas in which we serve, and to nurture and improve the quality of life of children and youth from impoverished target areas and then take the Jikeleza successful model and implement in areas that are riddled with poverty and crime through the medium of creative dance and music. (http://www.jikelezaprojects.co.za)

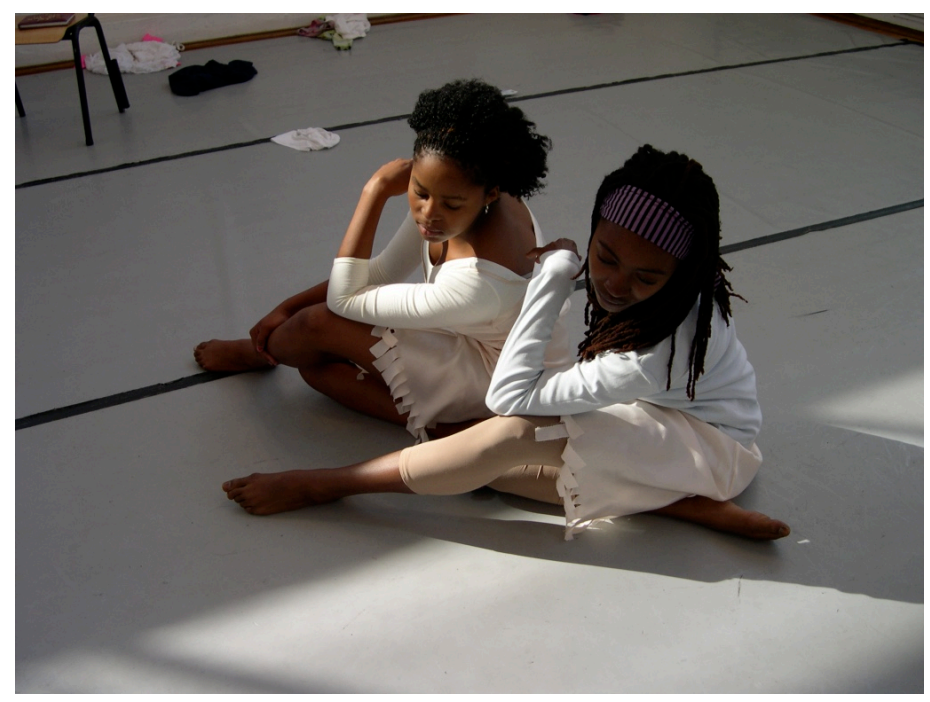

Figure 3: Dancers in the new South Africa 
The other groups of dancers came from the University of Cape Dance Program. The different groups of students did not know each other, so the beginning sessions were directed towards sessions that made the dancers comfortable and to feel a sense of safety.

\section{Threads through the process}

Movement instructions in the first classes were kept to abstract improvisations that eventually led to them acknowledging each other's presence in the space. I provided each of them with a journal and colourful markers where they could write down thoughts, feelings and responses to questions that I used to direct them towards thinking about who they are, and later more specifically about their hair. Reflective questions are a powerful pedagogic tool in this process. I teach out of this recognition as Elie Wiesel (1960, p. 86) 1982, shared, “... every question possesses a power that does not lie in the answer". I asked the dancers to write about their hair; how they think about it, and how they felt about it. From their written work, they chose three words or phrases to create a short movement phrase. After the creating their phrases, they shared them with each other and spoke about how they felt and thought about their hair. They shared their hair stories. I selected a section to read from a talk Alice Walker had given at Spelman College (1987) in Atlanta Georgia titled "Oppressed Hair Puts a Ceiling on the Brain." I asked then to talk about 'perfect' hair and where pressures 'to get hair' 'to be' something other than its natural state, come from? The dancers with blond hair spoke of the stereotype of dumb blondes and the dancer with dreadlocks shared experiences of not getting jobs because us her hair that was considered to be part of a way of being (in the dance she uses the phrase smoking ganga weed which would have made her, in the employer's notion, an undesirable and irresponsible employee.). She connected her hair to economic disempowerment. We looked at magazines and talked about the ideal image of beauty and where this beauty aesthetic comes from and how Western ideas of beauty often dominate the globe. I asked them what hair symbolised. The young women from the township shared stories of spending hours getting their hair straightened and suffering through the smelly and timely processes as they tried to look the preferred social image of women. I read to them a section from Susan Brownmiller's book Femininity (1984). I showed them an assortment of pictures of women of colour, what their culture refers to as white, black or coloured. I asked them what they 
'saw' when they looked at these pictures and how it made them feel. I asked them to talk about what the pictures were saying to us.

I draw on John Berger's work as he conveys the life-world of the subjects in a photograph to tell us something about the culture (Another Way of Telling, 1982). We look at the South African issue of Elle that has Beyoncé on the cover and I asked them to talk about how they would define her identity. Some said she was black, some said white and some others defined her identity as coloured, all making reference to her straight hair. During all of this the dancers were writing reflections, creating movement, sharing, learning each other's movements, and talking about their thoughts and discoveries. What was becoming clear was a tension between who is considered to be South African. They began to move beyond their individualist awareness to the connections between their shared worlds. As they learned to move the stories of each other's lives they became more connected. They listened and they heard. They laughed and they began making bodily contact through dancing. I purposefully added a class with some contact improvisation, as they had been shy about moving beyond the cultural boundaries of touching each other. They touched each other's hair, often for the first time having felt the differences between the silken lengths that lie flat to the kinky textures that curl every which way.

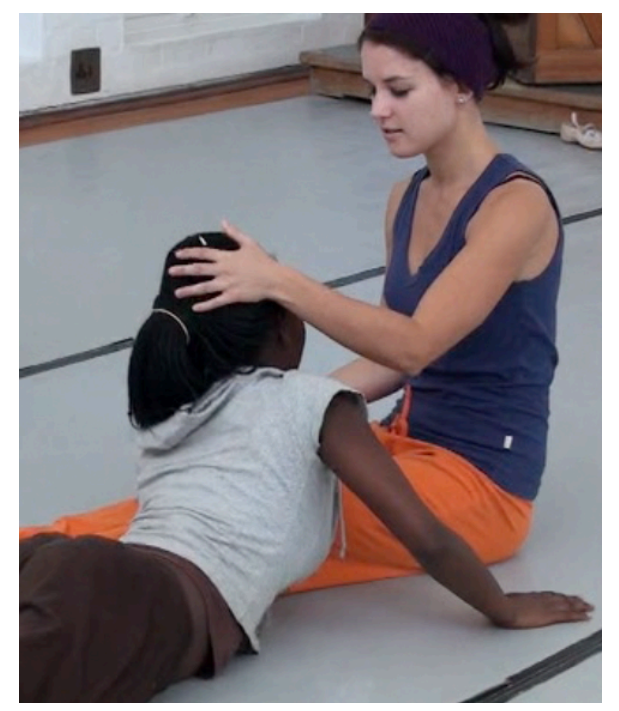

Figure 4: Exploring hair

Hair, our hair, is something that labels us, can give us pleasure and strife, and is something that as being female we struggle with most everyday. And, it often determines how we feel about ourselves. 'Bad hair days' has, across cultures, become a commonly understood expression for denoting our mood, sense of agency 
and our attractiveness. They felt, they listened, they spoke and they danced. Together, over this period, they created a dance that told their stories.

\section{The performance}

Moving the dance from the closed and protected space of the studio to the stage, demands thoughtful preparation. The dancers move the dance to one that is in the process of becoming to one that is. As the choreographer, I selected movements that have been created by the dancers, organised them into sequences and patterns, and put them into an order hoping to create an honest representation of what was created in our time together. I selected the music and costuming as well as the Program Notes vii. (You may see a video about the process of making the dance on YouTube viii)

\section{Endings}

The performance given for the larger community began with a talk by me helping to situate the audience into our larger discussion. I shared with them that in South Africa, just as in the United States and in so many other countries, girls and women are often valued by their physical appearance, as an object. And, in the field of dance, bodies are often 'used' simply as an instrument of the choreographer. So here in this process, the dancer is valued not simply as a 'body' but instead her experiences are valued and this makes it possible for us to reposition ourselves in turns of power. And when we begin to understand how we are shaped by culture our position to power changes-where we are no longer simply acted upon-but can take actions ourselves. We discussed the many different historical laws that had prevented women from owning property, having a bank account, voting, serving on juries, gaining access to higher education-and many other rights given to men. Even though today in many parts of the world these barriers have been crossed, in some countries women still cannot attend higher education, vote, own property, even drive a car, and face honor killings or prison for acts that men take upon them. So, I tell the audience, part of my work has been to educate women about women's history, but even more about their lives; what shapes how they think, feel and act. I try to help them experience their own bodies as subjects of their world, not mere objects to be seen and used. I value their voice. I embody their knowledge. I tell them I hope that from this experience the dancers have learned how to use their own critical lens to educate themselves about who they are, how 
they came to be that person, and become responsible to either accept how things are or act for change. It is a process meant to curb feelings of alienation and despair turning them outwards to recognise their allies and move toward connection, healing and change. I shared this quote from Marianne Williamson, author and political teacher quoted, "In every community, there is work to be done. In every nation, there are wounds to heal. In every heart, there is the power to do it" (Retrieved from http://www.inspiringquotes.us/author/6711-mariannewilliamson). I tell them, it has been my work as an artist to mirror the world we experience, and at times, imagine something different. And further, here in the performance that night they will find voices of those who know something about the world of female identity in Africa.

We ended the performance with the dancers coming onto stage to have a conversation with the audience. There were many hair stories from the audience. We listened about the choice of women to shave their heads, we struggle through a discussion about young white women who wanted to claim their South African identity along side the South African blacks, and we laughed. They asked the dancers specific questions about their parts in the dance. Together we honoured the work of the dancers who shared some of their world as they told some of their life-story through movement.

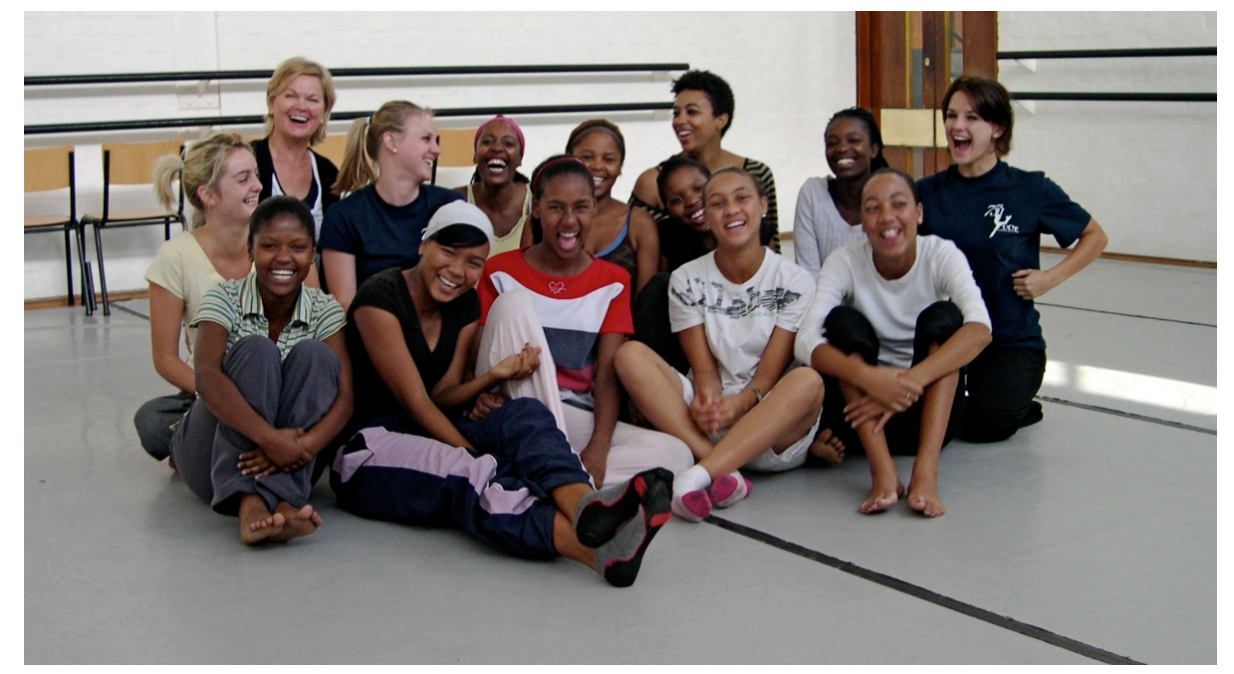

Figure 5: Dancers with Sherry Shapiro (back left)

After the performance, I met with the dancers completing my work with a final interview ${ }^{\text {ix }}$ asking them to talk about how this community dance project was similar to or different from other dance performances in which they had been involved. I asked them to talk about what they learned about themselves, others, and their culture. They told me of their transformations, their strength, how they 
developed new understandings and new friends. The dancer did not document her life - but moments of lived experience, as she told the story.

Aesthetic activism, yes, art and politics become linked. Maybe the form or the product would not be recognised as such, but the content and the process melds together threads of consciousness and the body to surpass what is hoped for. My belief is that there is no real ending to such a process. I expect that as the dancers return to their 'normal' lives subject to all the conventional cultural messages some of the immediate impact of the dance process will be lost. Yet, I remain convinced that once questions are posed, ideas deconstructed, beliefs challenged, connections made, there remains embedded within them an embodied knowing that has transformative power. I am reminded here of the work of the great English critical scholar, Raymond Williams, who talked of a 'long revolution'. By this, he meant the slow chipping away at ideas and beliefs that are buried deep within us and the continuing possibility of reimagining our lives and our world. Not withstanding the ups and downs of hope and change in our world, I remain committed to the concept of a pedagogy that may enable our students to not only critique their world, but to seek new meanings for their lives.

\section{CODA}

As I listened to the news, I continue to hear stories of struggle for girls and women around the world. For example, recently I heard the President of Turkey advise the Muslim women of Turkey to stop taking birth control and have more babies in order to populate the region with this particular nationality and religion. This, like so many other stories that we confront, illustrates the struggles that must be engaged with as we work for equality for all women as well as other marginalised, oppressed or disempowered groups. I share this here as I reflect upon my work in New Zealand and in this journal, recognising that we need to continue to think critically, engage in a dialogue of resistance and solidarity, call upon our lived experiences and find avenues to act through our art in ways that speak out and find commonalities to resist oppressive and harmful situations. All of this brings us to call upon our powers of connection across borders, to develop compassionate as well resisting communities, and to act through our work as artists and teachers in the spirit of love and justice.

Life can only be understood backwards; but it must be lived forwards. (Søren Kierkegaard, as translate by Hannay, 1986, p. 63 and 161). 
As Kierkegaard examined our ways of knowing, noting that in order to understand life we must look backwards. But as many activists and feminists remind us, we must 'look backward' to recall, reflect, critically analyse, interpret and make meaning of our past in any attempt to move forward with thoughtful intentions in an act towards aesthetic of commitment.

\section{References}

Berger, J. (1982). Another way of telling. New York, NY: Pantheon Books.

Bordo, S. (1993). Unbearable weight. Berkeley, CA: University of California Press.

Brownmiller, S. (1985). Femininity. New York, NY. Ballantine.

Collins, L. (2006). Activists who yearn for art that transforms: Parallels in the black arts and feminist art movements in the United States. Signs. Journal of Women in Culture and Society, 31(3). Retrieved from http://www.journals.uchicago.edu/doi/abs/10.1086/498991

Gottschild, B. (2008). Five dancemakers who dare to mix activism with art. Dance Magazine, 82(1), 62-68.

Dworkin, A. (1987). Intercourse. London, England: Arrow Books.

Eagleton, T. (1990). The ideology of the aesthetic. Oxford, England: Basil Blackwell.

Eagleton, T. (1996). The illusions of the postmodern. Oxford, England: Blackwell.

Foucault, M. (1977). Discipline and punishment. New York, NY: Random House.

Freire, P. (1998). Pedagogy of freedom: Ethics, democracy, and civic courage. Oxford, England: Rowman \& Littlefield.

Grauer, R. (Executive Producer). (2013). The individual and tradition. Thirteen/WNET, RM Arts, \& BBC-TV.

Greene, M. (1988). The dialectic of freedom. New York, NY: Teachers College Press.

Giroux, H. A., \& Simon, R. I. (1988). Schooling, popular culture, and a pedagogy of possibility. Journal of Education, 170(1), 9-26.

Green, M. (1988). The dialectic of freedom. New York, NY: Teachers College Press.

Hannay, A. (Trans). (1986). Soren Kierkegaard: Papers and journals: A selection. London, England: Penguin Books.

hooks, bell. (2000). all about love, new visions. New York, NY: William Morrow \& Co.

In every nation there are wounds to hear. (n.d.). Retrieved from http://www.inspiringquotes.us/author/6711-marianne-williamson

Kanpol, B., \& McLaren, P. (Eds.). (1995). Critical multiculturalism: Uncommon voices in a common struggle. Westport, CT: Bergin \& Garvey.

Keleman, S. (1981). Your body speaks its mind. Berkeley, England: Center Press.

Kuppers, P. (2006) Community dance-A resource file. Wellington, New Zealand: DANZ.

Lippard, L. (1995). The pink glass swan: Selected feminist essays on art. New York, NY: New Press.

MacDonald, J. (1965). Theories of instruction. Washington, DC: Assoc. for Supervision and Curriculum Development.

McLaren, P. (1988). Schooling the postmodern body: Critical pedagogy and the politics of enfleshment. Journal of Education, 170(3), 53-83.

Rosenberg, T. (2009). On feminists activist aesthetics. Journal of Aesthetics and Culture, I. doi: $10.3402 /$ jac.v1i0.4619

Shapiro, S.B. (2015). Art in a world of change: A vision for global aesthetics. Journal of Gender and Power, 3(1), 67-88.

Shapiro, S., \& Shapiro, S. (2002). Body movement: Pedagogy, politics and social change. Creskill, NJ: Hampton Press.

Shapiro, S. B. (1999). Pedagogy and the politics of the body: A critical praxis. New York, NY: Garland Publishing.

Smith, D. (1999). Zygmunt Bauman: Prophet of postmodernity. Oxford, England: Blackwell Publishers. 
Tutu, D. (2014, April 14). Archbishop Desmond Tutu. (Dr. Frank Lipman, Interviewer). Dr. Frank Lipman, The Voice of Sustainable Wellness. Retrieved from http://www.drfranklipman.com/archbishop-desmond-tutu/

Weiler, K. (1988). Women teaching for change. Westport, CT: Bergin and Garvey.

Welch, S. (1985). Communities of solidarity and resistance. New York, NYT: Doubleday.

\footnotetext{
i Protestors carrying placards at a Black Lives Matter demonstration in New York City. $28^{\text {th }}$ November 2014. https: //www. flickr.com/photos/otto-yamamoto/15305646874/

ii Members of the Ukrainian feminist political collective Femen brought a pre-Giuliani feel to Times Square in New York this week with an anti-Putin protest. Springtimeofnationas.blogspot.com

iii Arab Spring. (March 18, 2011). New York Times. Retriever from http://www.nytimes.com/2011/03/18/world/middleeast/18youth.html

iv http://www.bbc.com/news/world-latin-america-17847134

$\checkmark 1975$ Maori Land March poem by Hone Tuwhare

vi Pearl Primus's Strange Fruit and Hard Time Blues

vii * Program Notes for hair southAfrica

Section One: Early Memories

Remembering our hair when we were young - cut, plucked, dyed, straightened, braided, greased, bleached, tinted, dyed and decorated. We learn early that hair is the medium that signifies conformity or rebellion, youth or old age, restraint or freedom.

Section Two: Voices in the Head

Powerful messages become internalised; who decides how I should look, or what is considered attractive? Cultural forces determine beauty, aesthetic values, the construction of gender, and sometimes, even our economic futures.

Section Three: Making Waves

Moments of awareness are also times of possibility. As we come to understand ourselves in the context of culture, so we create spaces in which to affirm our identity and choose our future.

Section Four: Hair on My Mind

Identity is who we are in relationship. So, how do others see me? By my culture? Do I impress or am I invisible? Am I a threat or am I "safely" feminine?

viii hair southAfrica

ix See YouTube: Dance Research as Praxis
} 